Article

\title{
On the High Formability of AZ31-0.5Ca Magnesium Alloy
}

\author{
Umer Masood Chaudry, Tae Hoo Kim, Sang Duck Park, Ye Sik Kim, Kotiba Hamad * \\ and Jung-Gu Kim *
}

School of Advanced Materials Science \& Engineering, Sungkyunkwan University, Suwon 16419, Korea; umer@skku.edu (U.M.C.); eric9707@skku.edu (T.H.K.); chage123@skku.edu (S.D.P.); mgtopia@skku.edu (Y.S.K.)

* Correspondence: hamad82@skku.edu (K.H); kimjg@skku.ac.kr (J.-G.K.)

Received: 13 October 2018; Accepted: 5 November 2018; Published: 7 November 2018

check for updates

\begin{abstract}
In this work, we investigated the effect of Ca on the formability of the AZ31 Mg alloy. For this purpose, the microstructure, texture, mechanical properties and formability of AZ31 Mg alloy samples containing $0.5 \mathrm{wt}$. \% Ca (AZ31-0.5Ca) were studied. For comparison, the performance of Ca-Free AZ31 alloy samples with similar grain size was also investigated. In addition, formability of this alloy was reached at a high punch speed. The results of this work showed that the addition of $0.5 \mathrm{wt}$. \% Ca can enhance the formability of the AZ31 alloy, which was three times greater than that of the Ca-Free AZ31 alloy. The improved formability was attributed to the formation of $(\mathrm{Mg}, \mathrm{Al})_{2} \mathrm{Ca}$ particles $(\sim 1 \mu \mathrm{m})$, which, in turn, contribute to reducing the intensity of the strong basal texture during the primary processing of the alloy. The in-grain misorientation axis analysis determined by electron back-scattered diffraction and critical resolved shear stress calculations carried out by the viscoplastic self-consistent model showed that the non-basal slip systems could be activated in the AZ31-0.5Ca alloy.
\end{abstract}

Keywords: AZ31-0.5Ca alloy; microstructure; texture; plastic anisotropy; formability

\section{Introduction}

For reducing the oil consumption and avoiding the related environmental problems, scientists are always looking for lightweight structural materials that show high performance during both processing and application. Among the various candidates, $\mathrm{Mg}$ seems to be the most promising to achieve this target where it is $\sim 33 \%, 60 \%$, and $75 \%$ lighter than $\mathrm{Al}$, Ti, and steel, respectively. On the other hand, the poor ductility and high mechanical anisotropy of $\mathrm{Mg}$ limit its potentiality in several fields [1]. One example showing the effect of this limitation on the applicability of $\mathrm{Mg}$ was reached a long time ago. In 1935, Bugatti Aerolithe, which is one of the most beautiful and amazing cars ever built, was designed in the Volkswagen Beetle by Jean Bugatti. In this design, $\mathrm{Al}$ alloys, which were used to build the car bodies before World War II, were totally replaced by an Mg alloy (Elektron Mg alloy). This alloy had a high strength-to-weight ratio, which can be comparable to those of other materials used for the manufacturing of car bodies. However, the Bugatti Aerolithe was more expensive when compared to the other cars and, ever since, it has remained less usable. The high cost was mainly related to the low formability of the $\mathrm{Mg}$ alloy used to build the car where a special interest had to be paid during the processing of different parts. Most of the works reported on the formability and ductility of $\mathrm{Mg}$ alloys concluded that the weakening of the basal texture [2] and/or reducing the critical resolved shear stresses (CRSS) of the non-basal slip systems (prismatic and pyramidal) are the key points to enhance the performance of $\mathrm{Mg}$.

Several methods like reducing the grain size during primary processing [3] or alloying with different elements were used to modify the texture and CRSS to improve the formability of $\mathrm{Mg}$ 
alloys. Among these methods, the incorporation of rare earth (RE) elements was found to be a very promising method [4]. However, due to their high cost and incompatibility with recycling constraints, the applicability of $\mathrm{Mg}$ alloys containing RE elements is still limited in several fields. Alternative, non-RE elements were used to control the texture evolved after a primary processing and to enhance the formability of $\mathrm{Mg}$ alloys. Among the various investigated candidates, Ca showed high potentiality for improving the performance of $\mathrm{Mg}$ alloys [5]. In general, the alloying of Ca with pure $\mathrm{Mg}$ or $\mathrm{Mg}$ alloys can result in stable intermetallic compounds, which, in turn, enhance the grain refinement and texture weakening during the primary processing [6]. Recently, POSCO Mg Inc. has developed an Easy-formable (E-form) Ca-modified AZ31 Mg alloy sheet by a low cost twin roll casting process and succeeded to apply this alloy to the automotive industry [7]. The newly launched $\mathrm{Mg}$ alloy (AZ31-0.5Ca Mg alloy) showed improved performance in terms of the room-temperature formability. In order to clarify the main mechanisms responsible for this improved performance, additional studies are still needed. Accordingly, the experiments conducted in the present work were designed to figure out these mechanisms and to give better understanding of the intrinsic effect of $\mathrm{Ca}$ in addition to the formability of the AZ31 Mg alloy.

\section{Methods}

\subsection{Materials and Characterization}

The AZ31-0.5Ca alloy sheets with 1-mm thickness used in the present work were provided by POSCO Mg Inc (Pohang, Korea). For comparison, Ca-free AZ31 Mg alloy sheets ( 1 mm) with a similar microstructure were also investigated. The composition of the two alloys is shown in Table 1. For microstructure and texture evolution, samples cut from the transverse direction-rolling direction (TD-RD) plane of the sheets were mechanically grinded and polished by using a cross section polisher (Hitachi IM4000, Tokyo, Japan). The polished samples were then examined by using electron back-scattered diffraction (EBSD) in a scanning electron microscope with a field-emission gun (Hitachi S-4300 FESEM, Tokyo, Japan) and the data was analyzed by using TSL OIM 6.1.3 software (V8, EDAX Corporate, Mahwah, NJ, USA). For an accurate measurement, the EBSD scanning was carried out with a small step size $(0.05 \mu \mathrm{m})$. For texture evolution, the data acquired from the present EBSD experiments were transformed into the orientation distribution function (ODF) utilizing the harmonic series expansion method. These analyses were carried out in a Euler angle space $\left(\phi_{1}=0-90^{\circ}\right.$, $\Phi=0-90^{\circ}$, and $\phi_{2}=0^{\circ}$ ) by using the non-orthonormal sample symmetry. The measurements of grain size, the misorientation angle, and texture were taken from three different maps including 2000 grains. Room-temperature tensile tests (ASTM E646-98) were carried out on dog-bone specimens cut from the sheets of the two alloys (AZ31 and AZ31-0.5Ca) along three different directions including $\mathrm{RD}, 45^{\circ}$ from RD and TD. Mechanical anisotropy of the alloys was investigated by analyzing the deformation behavior of the samples at $10 \%$ tensile strain. Accordingly, the Lankford values (r-value), the average $r$-value $\left(r_{\text {avg }}\right)$, and the planar anisotropy $(\Delta r)$ were determined by using the following equations.

$$
\begin{gathered}
r=\frac{\varepsilon_{w}}{\varepsilon_{t}} \\
r_{a v e}=\frac{1}{4}\left|r_{R D}+r_{T D}+2 r_{45}\right| \\
\Delta r=\frac{1}{2}\left|r_{R D}+r_{T D}-2 r_{45}\right|
\end{gathered}
$$

where $\varepsilon_{w}$ and $\varepsilon_{t}$ are the true width and thickness strains at $10 \%$ tensile deformation, respectively, and $r_{R D}, r_{45}$, and $r_{T D}$ are $r$-values are along the three different directions. Erichsen cupping tests were conducted on $90 \mathrm{~mm} \times 90 \mathrm{~mm}$ sheets at room temperature using two different punch speeds $(0.33 \mathrm{~mm} / \mathrm{s}$ and $0.08 \mathrm{~mm} / \mathrm{s})$. The results of five tests were averaged to obtain the Erichsen value of each alloy. The conditions of Erichsen tests are presented in Table 2. 
Table 1. The composition of AZ31 and AZ31-0.5Ca alloys.

\begin{tabular}{ccccccccc}
\hline Alloy & Al & Zn & Ca & Si & Mn & Fe & Cu & Mg \\
\hline AZ31 & 2.99 & 0.73 & - & 0.024 & 0.20 & 0.0026 & 0.0003 & Bal. \\
AZ31-0.5Ca & 3.12 & 0.76 & 0.5 & 0.023 & 0.31 & 0.0042 & 0.0012 & Bal. \\
\hline
\end{tabular}

Table 2. The conditions of the Erichsen test used in the present work.

\begin{tabular}{ccccc}
\hline Load $(\mathbf{k N})$ & Punch Size $(\mathbf{m m})$ & Punch Speed $(\mathbf{m m} / \mathbf{s})$ & Specimen Size $(\mathbf{m m})$ & Specification \\
\hline 350 & 20 & 0.33 & $90 \times 90$ & ISO 20482 \\
\hline
\end{tabular}

\subsection{VPSC Modeling}

The viscoplastic self-consistent (VPSC) model was employed to simulate the texture that evolved from the two alloys (AZ31 and AZ31-0.5Ca) after 10\% tensile deformation starting from 2000 discrete orientations taken from EBSD results of the non-deformed alloys (Figure 3). This occurred to predict the activity of various slip systems during the deformation (basal and non-basal slip systems) [7]. In this regard, the Voce hardening law (Equation (4)) was introduced in this model to calculate the CRSS of the slip systems. Accordingly, by increasing the CRSS of the sth system $\left(\tau^{s}\right)$ as a function of the total shear strain $(\Gamma)$ accumulated in the grain, the hardening response of individual slip and twinning systems can be modeled by using the equation below.

$$
\tau^{S}=\tau_{0}^{s}+\left(\tau_{1}^{s}+\theta_{1}^{s} \Gamma\right)\left(1-\exp \left(-\Gamma\left|\frac{\theta_{0}^{s}}{\tau_{1}^{s}}\right|\right)\right)
$$

where $s, \theta_{0} s, \theta_{1}^{s}, \tau_{0}^{s}$, and $\left(\tau_{0}{ }^{s}+\tau_{1}{ }^{s}\right)$ are the slip system, initial and final slopes of the hardening curve, initial critical resolved shear stress, and the back-extrapolated CRSS, respectively. In this work, only tension twins were considered for modeling because other twining systems such as compressive and double twins were unobservable after the $10 \%$ tensile deformation.

\section{Results}

\subsection{Formability}

Figure 1a shows the cups left after the room-temperature Erichsen tests were carried out on the AZ31 and AZ31-0.5Ca sheets at a punch speed of $0.33 \mathrm{~mm} / \mathrm{s}$. The addition of $0.5 \mathrm{wt}$. \% Ca significantly enhanced the formability of the AZ31 alloy where Erichsen values of $\sim 6 \mathrm{~mm}$ and $9 \mathrm{~mm}$ were recorded for the AZ31-0.5Ca alloy sheets and tested at punch speeds of $0.33 \mathrm{~mm} / \mathrm{s}$ and $0.088 \mathrm{~mm} / \mathrm{s}$, respectively. The Erichsen value of this alloy at $0.33 \mathrm{~mm} / \mathrm{s}$ is about three times higher than the value recorded for the AZ31 alloy at the same speed. For comparison, the Erichsen values recorded for several $\mathrm{Mg}$ and $\mathrm{Al}$ alloys are presented in Figure $1 \mathrm{~b}$ as a function to the punch speed [8-13]. Generally, due to the high hardening occurred at high punch speeds [10-13], low speeds $(<0.09 \mathrm{~mm} / \mathrm{s})$ are usually used in order to increase the formability limit of metallic sheets. As shown by Figure 1b, the AZ31-0.5Ca alloy investigated in the present work exhibited higher formability than other $\mathrm{Mg}$ alloys [8-11] and, more importantly, the improved formability was reached at a high punch speed $(0.33 \mathrm{~mm} / \mathrm{s})$. The Ca addition, accordingly, resulted in a high-rate-improved formability, which can be reached at room temperature. To understand the effect of the Ca addition on the formability of the AZ31 Mg alloy, the microstructure evolution, texture, and related mechanical properties of AZ31 and AZ31-0.5Ca alloys were investigated and discussed in the following sections. 
(a)

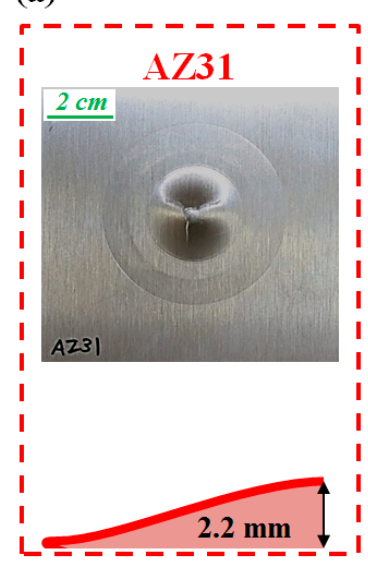

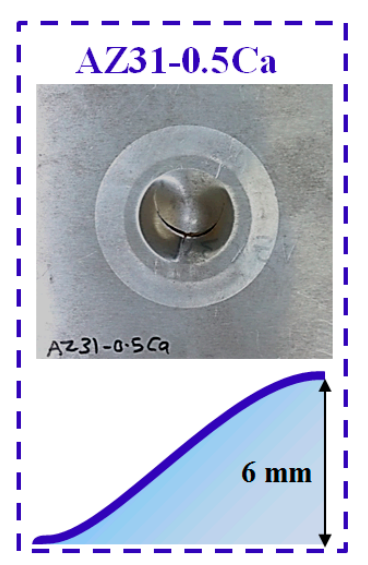

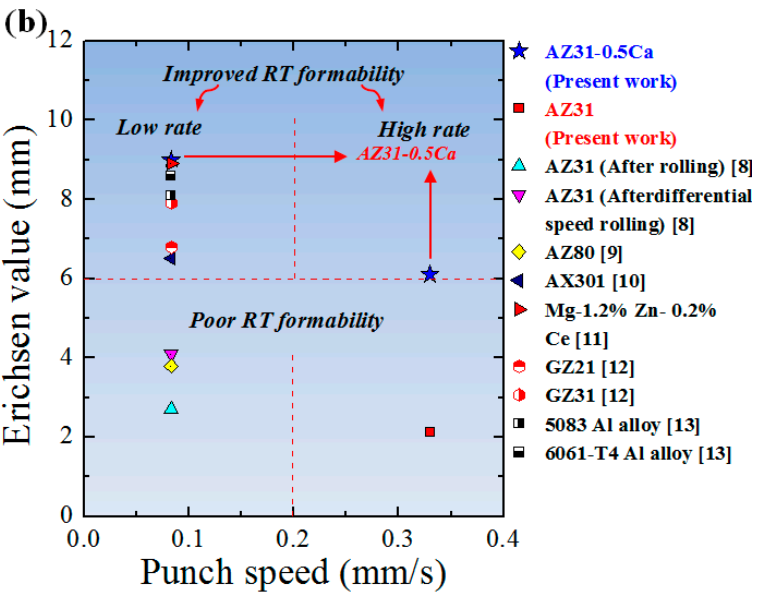

Figure 1. (a) Side views taken from the AZ31 and AZ31-0.5Ca alloy sheets after Erichsen test; (b) Comparison between Erichsen values of the AZ31-0.5Ca alloy studied in the present work with some other $\mathrm{Mg}$ and $\mathrm{Al}$ alloys.

\subsection{Microstructure and Texture}

Figure 2 shows the electron back-scattered diffraction (EBSD) data including the normal direction (ND) inverse pole figure (IPF) maps, image quality (IQ) maps, and grain size distribution of AZ31 and AZ31-0.5Ca alloys. It is clearly evident that both alloys have similar microstructural features including grain size and morphology (Figure 2a,d), which can also be confirmed from grain size distribution of both alloys (Figure 2c,f). On the other hand, two main variations can be noted, which is that the former is the higher number of randomly-oriented grains in the AZ31-0.5Ca alloy, as shown by the IPF maps (Figure 2a,d), and the latter is the presence of fine particles in the AZ31-0.5Ca alloy, which is shown by the low quality area in the IQ map in Figure 2e (indicated by red arrows). In the AZ31-0.5Ca alloy, randomly-oriented grains, which are those with the c-axis tilted away from the ND of the sample, indicate the weak basal texture evolved in this alloy. On the other hand, the initial texture of the AZ31 alloy investigated in the present work is characterized by more grains with basal orientations such as (0001) [1010], (0001) [11̄00], (0001) [0110], and (0001) [1230]. This can be clarified by (0001) pole figures (PF) and the orientation distribution function (ODF) maps of the AZ31 and AZ31-0.5Ca alloys obtained by EBSD, which is shown in Figure 3a,b,d,e, respectively. (0001) PFs of the alloys in Figure 3a,d show that the AZ31 alloy has a higher maximum intensity ( 13) as compared to the AZ31-0.5Ca alloy ( 5) with basal poles broadly distributed along the transverse direction (TD) of the sample. Reduced Euler space $\left(\phi_{2}: 0^{\circ}, \phi_{1}: 0-90^{\circ}, \Phi: 0-90^{\circ}\right)$ ODF maps presented in Figure $3 b$,e show the basal texture components $((0001)[10 \overline{1} 0],(0001)[1 \overline{1} 00],(0001)[0 \overline{1} 10]$, and (0001) [1230] (Figure 3g)) along $\phi_{1}\left(0-90^{\circ}\right)$ and the intensities of these components are weaker for AZ31-0.5Ca as compared to the AZ31 alloy in Figure 3b,e,h. Additionally, the partitioned maps of the basal-oriented grains (Figure $3 \mathrm{c}, \mathrm{f}$ ) show the evolution of fewer numbers of basal-oriented grains in the AZ31-0.5Ca (6\%) as compared to the AZ31 alloy (15\%). For the partitioning of basal-orientated grains, a tolerance angle of $5^{\circ}$ was used. Coming back to the above-mentioned variations, the fine particles observed in the IQ map of the AZ31-0.5Ca alloy are analyzed further by using scanning electron microscopy with energy dispersive spectroscopy (SEM/EDS). Figure 4a-c shows low and high magnifications SEM micrographs, the related EDS analysis, and the X-ray diffraction pattern of the two alloys. For the particle size distribution presented in Figure 4d, almost 200 particles distributed within the grains and on the grain boundaries were selected from different positions. The selection of these particles was carried out based on their composition (Figure $4 \mathrm{~b}$ ). The EDS measurements of these particles revealed that they are mainly composed of $\mathrm{Mg} \sim 40$ wt. $\%, \mathrm{Al} \sim 40$ wt. $\%$, and $\mathrm{Ca}$ $\sim 18$ wt. \% (Figure $4 \mathrm{~b}$ ). The present SEM/EDS data is consistent with the predication work carried out by Grobner and Schmid-Fetzer [14], which indicates that the addition of Ca to the AZ31 alloy can lead 
to the formation of an $(\mathrm{Mg}, \mathrm{Al})_{2} \mathrm{Ca}$ intermetallic compound [15]. In addition, this is consistent with the XRD patterns of the two alloys (Figure $4 \mathrm{c}$ ) where new peaks related to $(\mathrm{Mg}, \mathrm{Al})_{2} \mathrm{Ca}$ appeared in the AZ31-0.5Ca alloy [16]. The presence of such particles might induce the evolution of specific dynamic and static recrystallization behaviors during the primary processing of this alloy [17]. Based on this point, additional experimentation is still needed in order to clarify how these particles control the recrystallization behaviors of the AZ31-0.5Ca alloy.
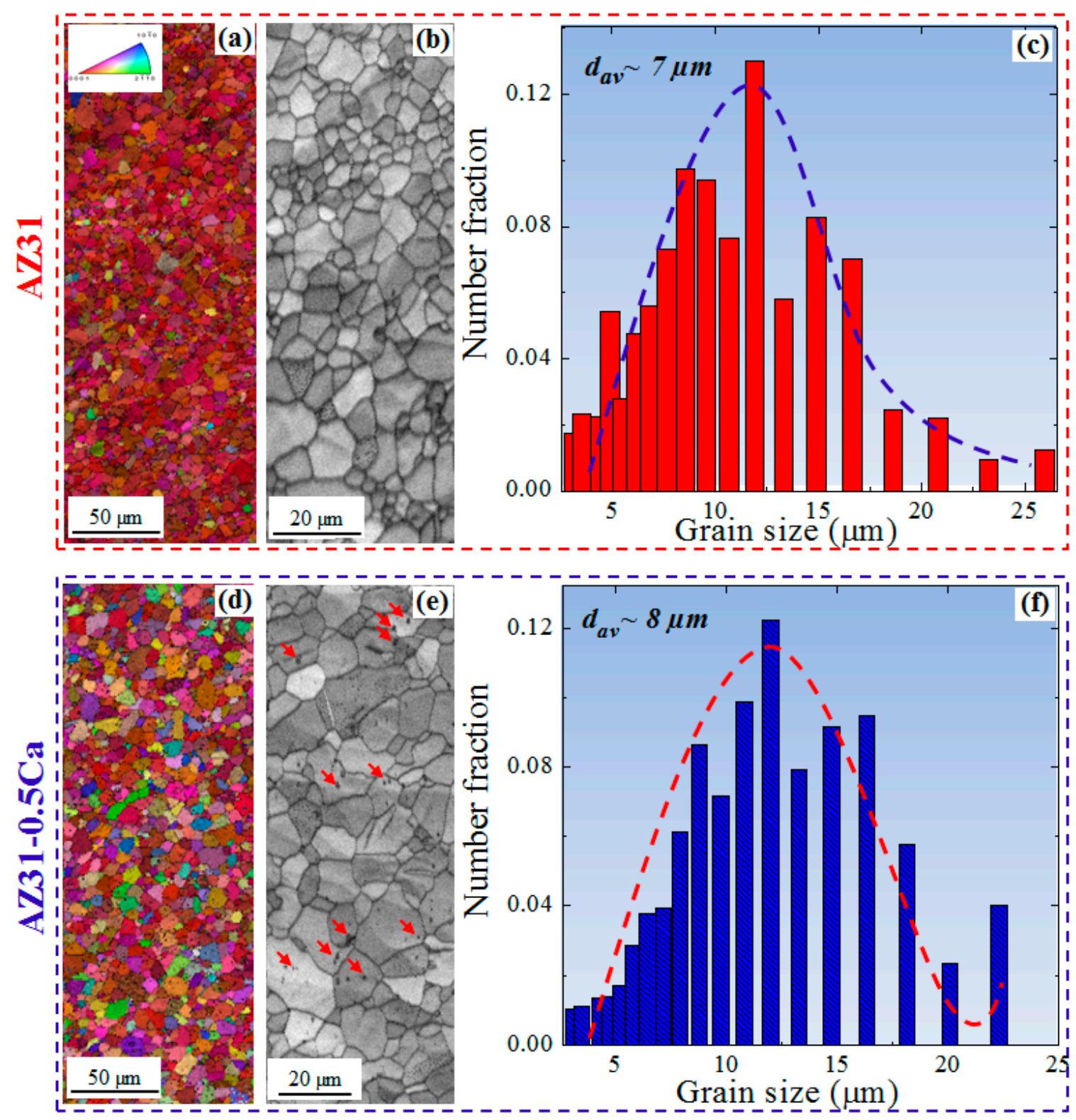

Figure 2. (a,d) ND inverse pole figure maps; (b,e) image quality maps; and (c,f) grain size distributions of the AZ31 and AZ31-0.5Ca alloys, respectively. The grain size measurements by EBSD experiment were conducted at a tolerance angle of $2^{\circ}$. 


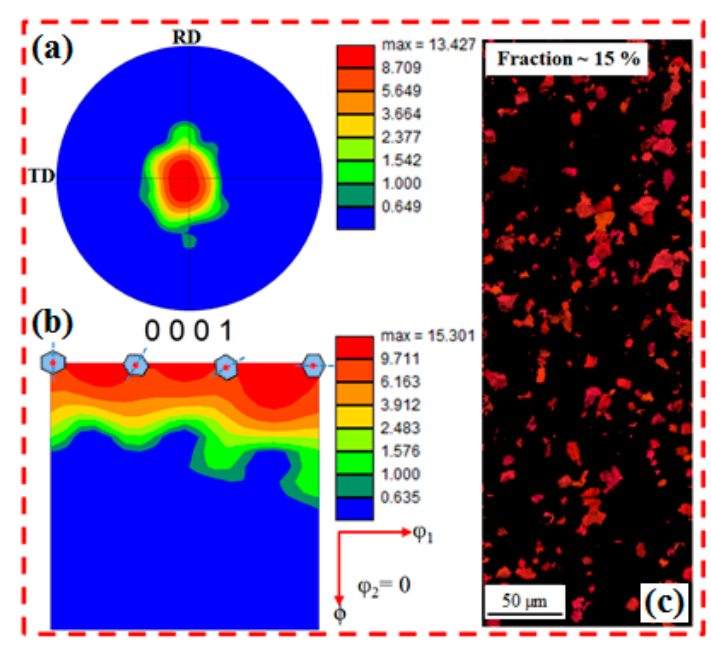

(g)
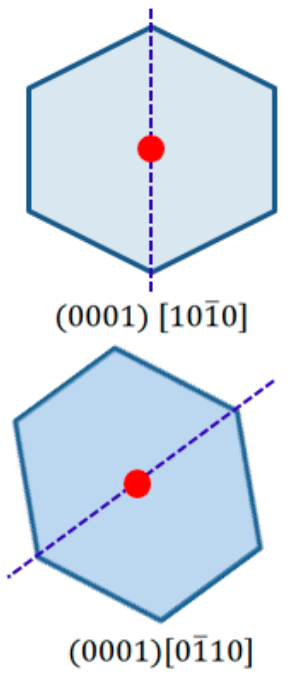
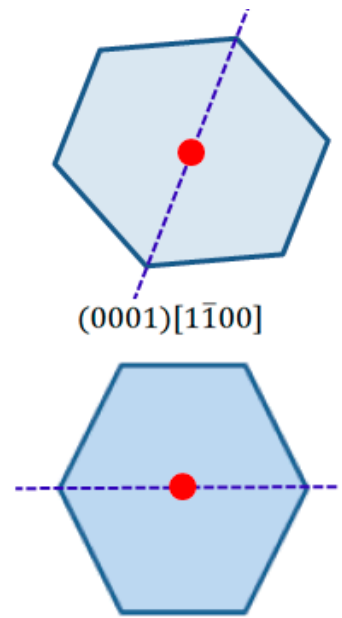

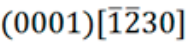
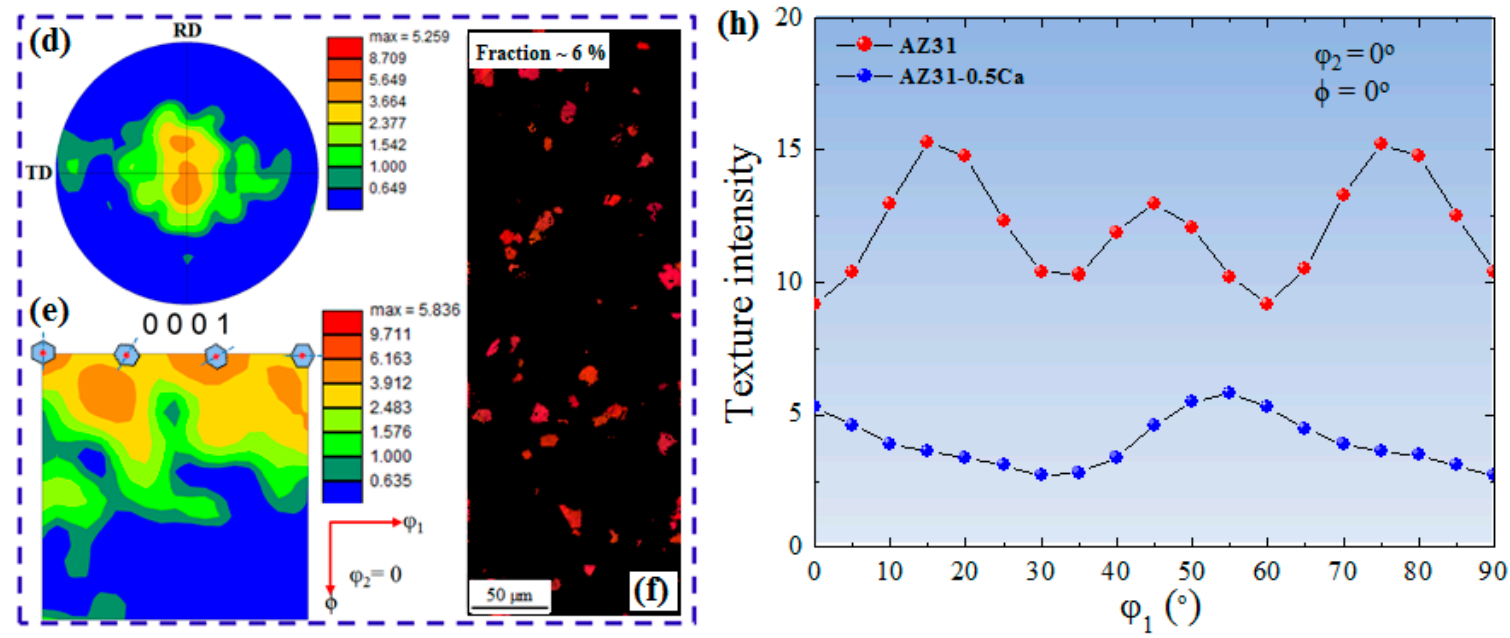

Figure 3. (a,d) Pole figures; (b,e) orientation distribution function; and (c,f) ND inverse pole figure maps of partitioned basal grains of the AZ31 and AZ31-0.5Ca alloys, respectively; (g) The main orientations of the basal texture; (h) Orientation distribution function intensity of the two alloys along $\phi_{1}\left(\phi_{2}=0^{\circ}, \Phi=0^{\circ}\right)$.

\subsection{Mechanical Performance}

Figure 5 shows room-temperature tensile curves of the AZ31 and AZ31-0.5Ca alloys tested along three different directions, which includes $\mathrm{RD}, 45^{\circ}$ from $\mathrm{RD}$, and TD. The tensile data including yield strength (YS), ultimate tensile strength (UTS), uniform elongation (UE), total elongation (TE), and the strain hardening exponent $(n)$ are listed in Table 3. Strain hardening exponents presented in Table 3 were calculated by using true stress-true strain curves of the alloys (not shown here). Generally, along the three directions, the AZ31-0.5Ca alloy is more ductile and weaker than the AZ31. For both alloys, AZ31 and AZ31-0.5Ca, the YS was the highest along RD, which was followed by TD and $45^{\circ}$, respectively. In addition, the two alloys show identical behaviors in which the TE was the highest along the $\mathrm{RD}$ followed by $45^{\circ}$ and TD. In order to clarify the effect of the composition and the related texture on the mechanical anisotropy, Lankford values ( $r$-value), the average $r$-value $\left(r_{\text {avg }}\right)$, and planar anisotropy $(\Delta r)$ of the alloys were determined and compared (Table 3). Although the two alloys nearly showed the same trend along the various directions, they have distinct mechanical anisotropy and strain hardening capabilities. With $r$-values and $\Delta r$ close to 1 and 0 , respectively, the AZ31-0.5Ca alloy exhibits a lower plastic anisotropy when compared to AZ31, as shown in Table 3. In addition, the strain hardening exponents of this alloy (AZ31-0.5Ca) along the three different directions are higher than 
those of the AZ31 alloy. The high strain hardening capability of the AZ31-0.5Ca alloy reduces the mechanical instabilities during plastic deformation and, hence, enhances the uniform ductility (shown in Table 3).
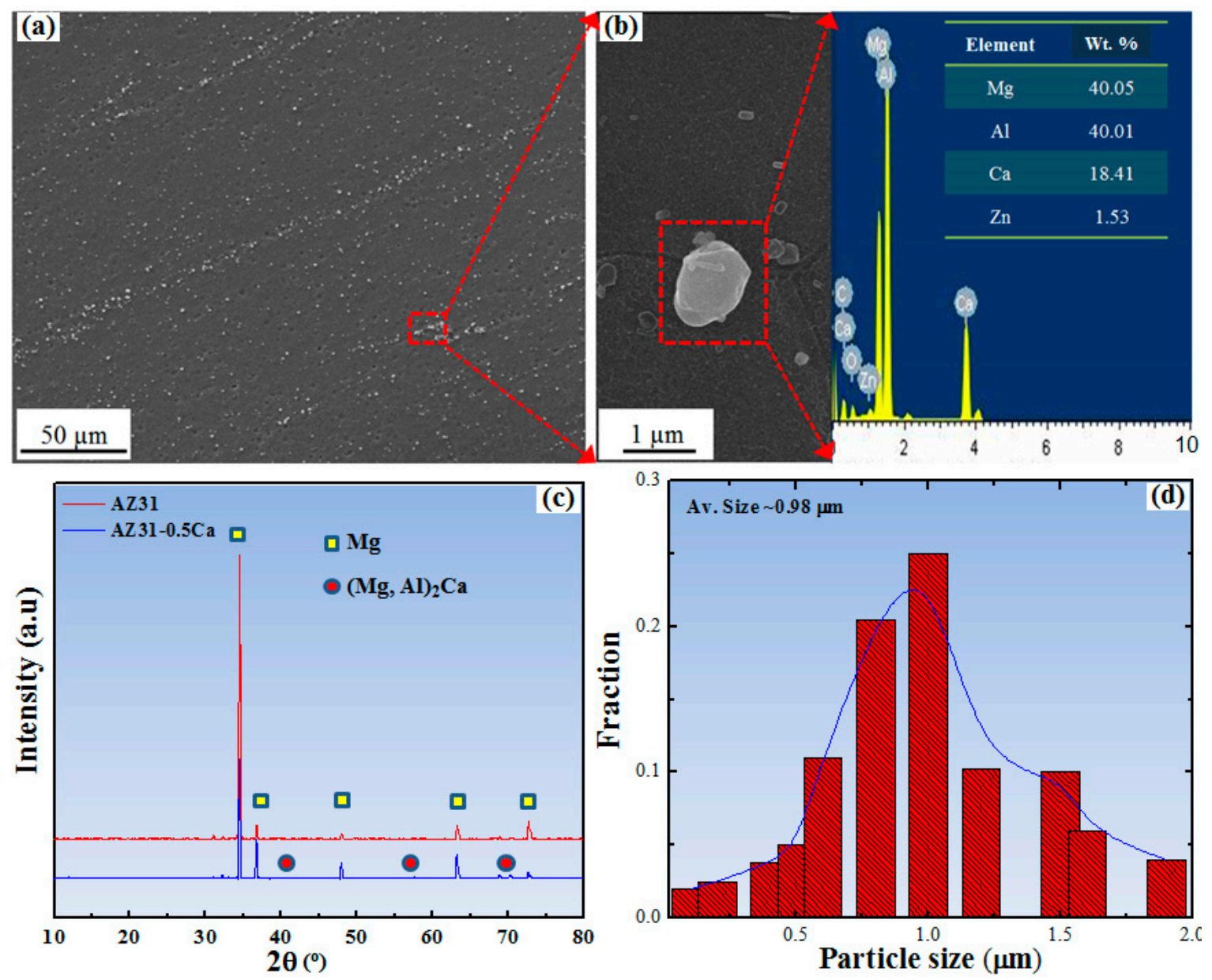

Figure 4. (a,b) SEM micrographs of the AZ31-0.5Ca alloy showing fine $(\mathrm{Mg}, \mathrm{Al})_{2} \mathrm{Ca}$ particles and the related energy-dispersive $\mathrm{X}$-ray spectroscopy taken on the particles [7]; (c) X-ray diffraction pattern of AZ31 and AZ31-0.5Ca; (d) $(\mathrm{Mg}, \mathrm{Al})_{2} \mathrm{Ca}$ particle size distributions in AZ31-0.5Ca.

Table 3. Room-temperature tensile properties and mechanical anisotropy parameters of AZ31 and AZ31-0.5Ca alloys. Strain hardening exponents presented in Table 3 were calculated by using true stress-true strain curves of the alloys (not shown here).

\begin{tabular}{cccccccccc}
\hline \multirow{2}{*}{ Alloy } & $\begin{array}{c}\text { Tensile } \\
\text { Direction }\end{array}$ & $\begin{array}{c}\text { YS } \\
\text { (MPa) }\end{array}$ & $\begin{array}{c}\text { UTS } \\
\mathbf{( M P a )}\end{array}$ & UE (\%) & TE (\%) & $\boldsymbol{n}$ & $\boldsymbol{r}$ & $\boldsymbol{r}_{\text {avg }}$ & $\boldsymbol{\Delta} \boldsymbol{r}$ \\
\hline \multirow{3}{*}{ AZ31 } & RD & 176 & 275 & 24 & 32 & 0.2 & 2.34 & & \\
& $45^{\circ}$ & 161 & 272 & 22 & 29 & 0.17 & 2.7 & 2.3 & 0.72 \\
& TD & 171 & 283 & 23 & 27 & 0.21 & 1.62 & & \\
\hline \multirow{2}{*}{ AZ31-0.5Ca } & RD & 147 & 248 & 31 & 38 & 0.28 & 0.71 & & \\
& $45^{\circ}$ & 125 & 237 & 30 & 35 & 0.27 & 0.52 & 0.6 & 0.16 \\
& TD & 139 & 251 & 30 & 32 & 0.26 & 0.69 & & \\
\hline
\end{tabular}




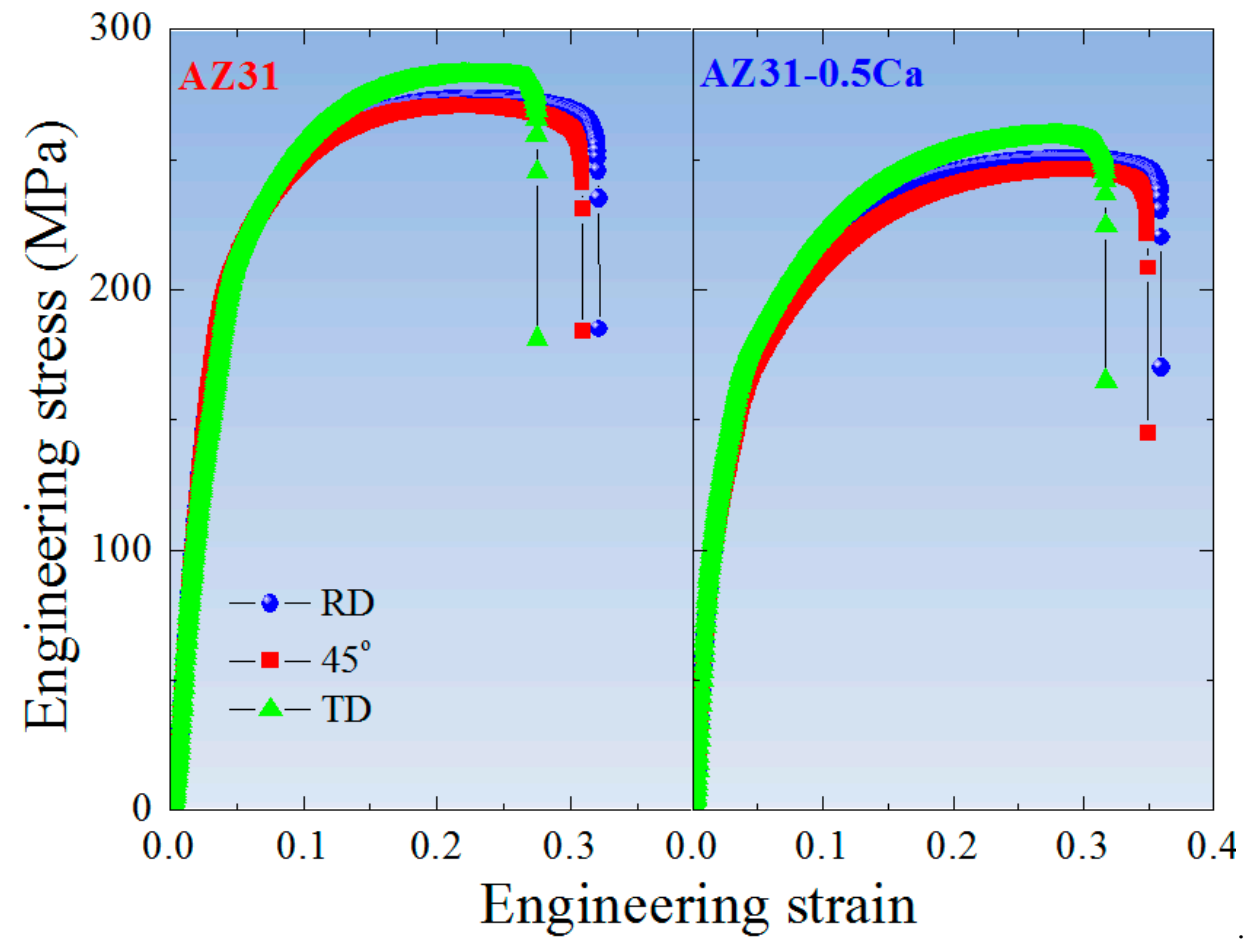

Figure 5. Room temperature engineering stress-engineering strain curves of the AZ31 and AZ31-0.5Ca alloys along $\mathrm{RD}, 45^{\circ}$ from $\mathrm{RD}$, and $\mathrm{TD}$.

\section{Discussion}

To figure out the improved formability recorded for the AZ31-0.5Ca alloy, the microstructure and texture evolution of the two alloys after a 10\% tensile deformation were investigated. Figure 6 shows the ND-IPF maps, IQ maps, and misorientation angle distributions of the two alloys tensile-deformed at $10 \%$ along the RD. For the comparison, the misorientation angle distributions of the non-deformed alloys were also included. It is clearly seen that both alloys show an evolution of boundaries, which are related to tension twins $\left(\langle\overline{1} 011\rangle\{10 \overline{1} 2\} \sim 86^{\circ}\right)$ after the tensile deformation. This was indicated by the red boundaries in the IQ maps (Figure $6 \mathrm{~b}, \mathrm{e}$ ). The fraction of these boundaries is a little bit higher in the AZ31-0.5Ca alloy sample ( 12\%) when compared to AZ31 ( 10\%) (Figure $6 \mathrm{c}, \mathrm{f})$. Tension twins, which act as a secondary deformation mechanism beside the basal slip, usually accommodate the extension along the c-axis. In addition, they can easily form in grains with a high Schmid factor and grow thickly to overtake the parent grains, which results in high ductility. Usually, $30 \%$ to $40 \%$ tension twins evolve after the $10 \%$ tensile deformation of weak-basal-textured pure $\mathrm{Mg}$ and its alloys [18]. In the present work, the low fraction of the tension twins observed for the AZ31 alloy $(\sim 10 \%)$ is attributed to its strong basal texture, which is shown by Figure 3 and by the Schmid factor maps for the basal slip (Figure 7). On the other hand, the 10\% tensile deformation of the AZ31-0.5Ca alloy with a weak basal texture leads to a lower fraction of tension twins ( 12\%) when compared to the fraction evolved in the weak-basal-textured $\mathrm{Mg}$ materials (30-40\%) after the same amount of deformation. This, in turn, confirms a possible contribution of non-basal slip to the deformation of the AZ31-0.5Ca alloy. To characterize the type of non-basal slip, which might be activated, the distribution of in-grain misorientation axes (IGMA) were determined for the deformed alloys [19]. IGMA analyses are used to identify the slip modes throughout a misorientation range between $2.5^{\circ}$ and $5^{\circ}$ where, in this range, the in-grain misorientations are mainly caused by the activation of slip systems [19]. An activation of a single slip in a crystal was considered in order to explain the relationship between the activated slip system and the IGMA. In general, the presence of dislocations can bend the crystal, which leads to a slight in-grain misorientation $\left(2.5^{\circ}-5^{\circ}\right)$ [19]. The in-grain misorientation due to a single slip can be described by the following equation. 


$$
r(s)=n(s) \times d(s)
$$

where $s$ is the slip system in which the dislocation is generated, $r$ is the Taylor axis around which the crystal is bent, $n$ is the axis of the slip plane, and $d$ is the slip direction. According to this equation, the characteristics of the crystal bending due to the single slip are mainly associated with the type of the slip. This can be shown by Figure $8 \mathrm{a}$ where two types of pure edge dislocations are considered including the $<\mathrm{a}>$ basal dislocation and the $<\mathrm{a}>$ prismatic dislocation. Based on Figure 8a, misorientation axes close to the $\langle 10 \overline{1} 0\rangle$ indicate a high activity of the $<$ a $>$ basal slip while the $<$ a $>$ prismatic slip is indicated by misorientation axes close to $\langle 0001\rangle$. Figure $8 \mathrm{~b}$ shows IGMA analyses of four different grains taken from the tensile-deformed AZ31 and AZ31-0.5Ca samples. The results clearly show that, after the tensile deformation, the distribution of IGMA of the grains selected from the AZ31 alloy is concentrated between $\langle 10 \overline{10}\rangle$ and $\langle 2 \overline{11} 0\rangle$, which indicates that the basal slip is the dominated deformation mode in this alloy. On the other hand, the distribution of IGMA of the grains selected from the AZ31-0.5Ca alloy are distributed around $\langle 0001\rangle$, which suggests that the prismatic slip is absolutely activated [20-23].

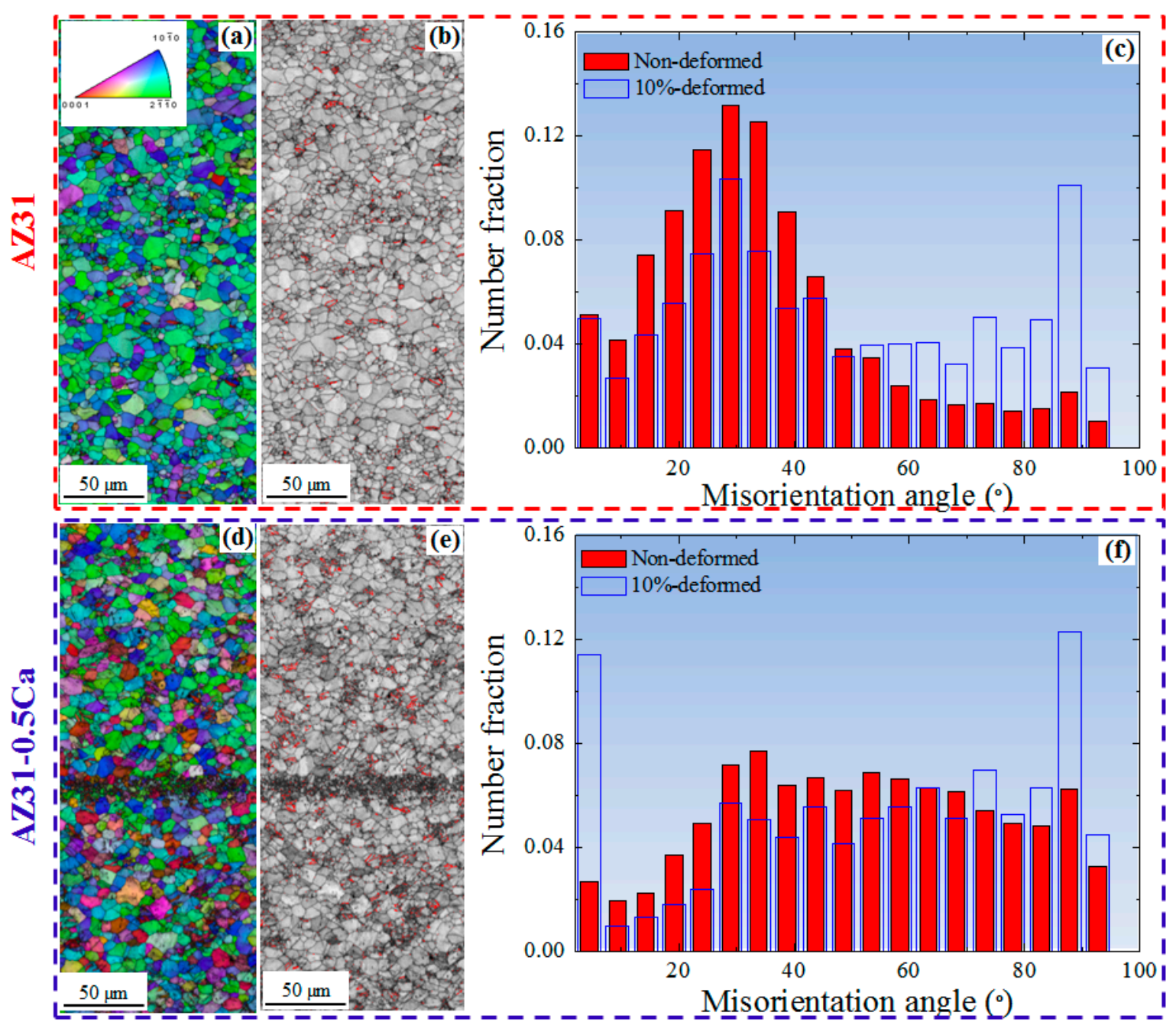

Figure 6. (a,d) ND inverse pole figure maps; (b,e) image quality maps; and (c,f) misorientation angle distributions of the 10\%-deformed AZ31 and AZ31-0.5Ca alloy, respectively. For comparison, the misorientation angle distributions of the initial samples (non-deformed) were also included. In addition, the tension twin boundaries $\left(\sim 86^{\circ}\right)$ were shown by the red lines in the image quality maps $(\mathbf{b}, \mathbf{e})$. 

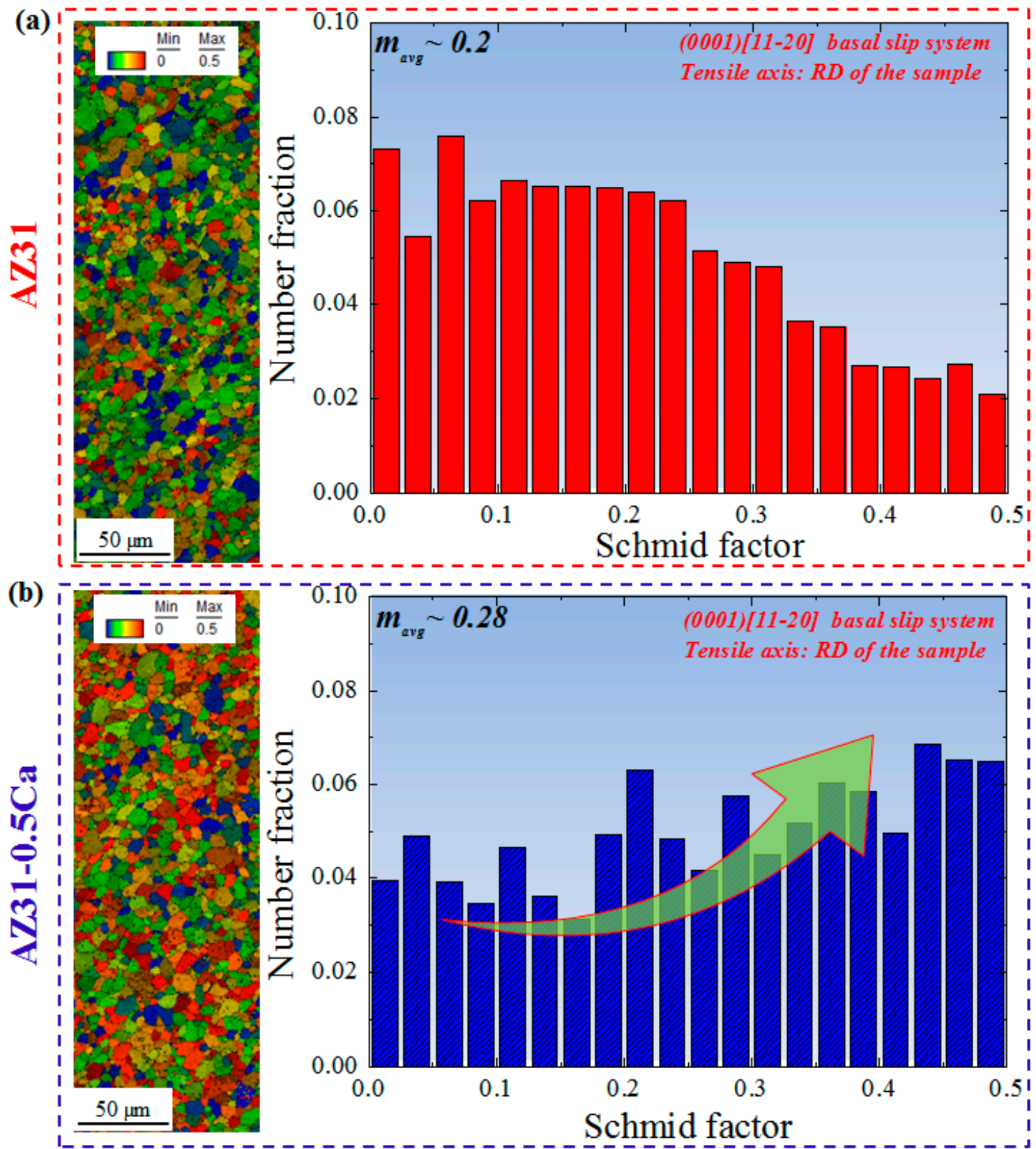

Figure 7. (a,b) Schmid factor maps and Schmid factor distribution of the AZ31 and AZ31-0.5Ca alloys, respectively. The Schmid factor was determined for the (0001) [11 20$]$ basal slip system along the RD as the tensile axis.

Several studies reported the effect of the composition on the activity of slip systems for various $\mathrm{Mg}$ alloys and related performance of these alloys. For example, Yuasa et al. [24] studied the effect of Ca addition ( $0.06 \mathrm{wt} . \%)$ on the formability and associated slip modes in the Mg-1.5Zn alloy. Their results showed that the improved formability of this composition $(\mathrm{Mg}-1.5 \mathrm{Zn}-0.06 \mathrm{Ca})$ was essentially attributed for the activation of the prismatic slip, which, in turn, is related to the role of Ca solutes in reducing the generalized stacking fault energy of this system. In the present work, however, a higher amount of $\mathrm{Ca}(0.5 \mathrm{wt}$. \%) was alloyed, which was above the solubility limit of $\mathrm{Ca}$ in $\mathrm{Mg}$ [25] and this addition resulted in the formation of the intermetallic compound, as shown by the EDS/SEM analysis (Figure 4). Accordingly, the effect of the $0.5 \mathrm{wt}$. \% Ca addition on the activity of the prismatic slip cannot be figured out based on the reduced generalized stacking fault energy. 


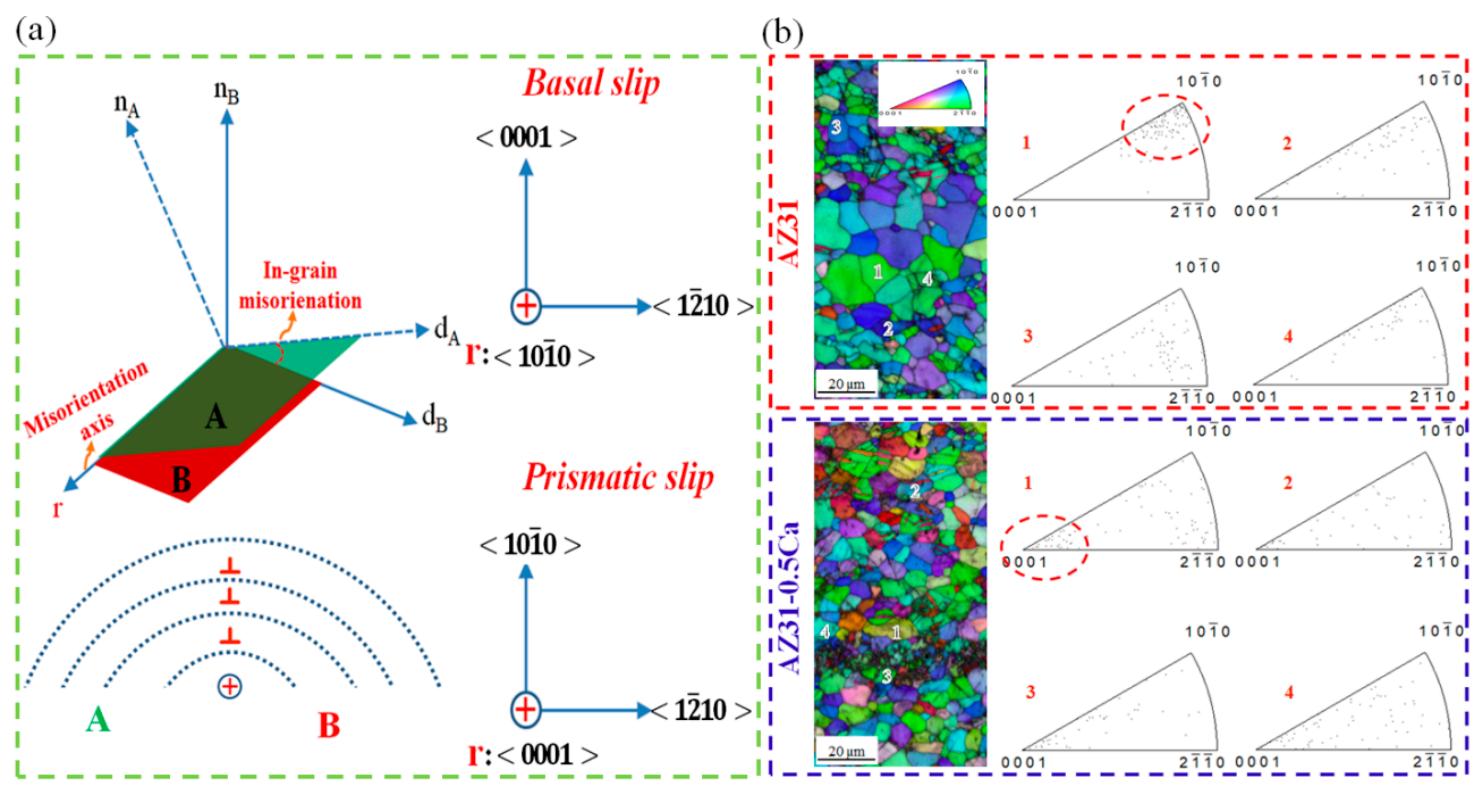

Figure 8. (a) Schematics showing the main concept of the relation between the in-grain misorientation axis and the activated slip system; (b) ND inverse pole figure maps and related in-grain misorientation axis analysis taken for four randomly-selected grains from the AZ31 and AZ31-0.5Ca alloys. The two examples indicated by the dashed circles (grains 1 in the AZ31 and AZ31-0.5Ca alloys) show the shifting of the misorientation axis toward $<0001>$ in the AZ31-0.5Ca and toward $\langle 2 \overline{11} 0\rangle-\langle 10 \overline{1} 0\rangle$ in AZ31.

As an alternative, the activation of the non-basal slip systems might be induced by changing the relative CRSSs (CRSS non-Basal $/$ CRSS $_{\text {Basal }}$ ) [26]. As compared to single-crystal Mg alloys, CRSSs of polycrystalline $\mathrm{Mg}$ alloys are related to the hardening contributions by grain boundaries, dislocations, and second-phase particles. Accordingly, for a polycrystalline $\mathrm{Mg}$ alloy, the actual value of CRSS (equivalent to that recorded at the yielding of the single-crystal $\mathrm{Mg}$ alloy) is given by the equation below.

$$
\tau=\mathrm{CRSS}+\Delta \tau
$$

where $\tau$ is the effective CRSS value obtained in a hardened state of the polycrystalline Mg alloy and $\Delta \tau$ is the shear stress related to the hardening contributions. For the single-crystal Mg alloys, $\Delta \tau$ is equal to zero and, hence, the CRSS of the basal slips $\left(\mathrm{CRSS}_{\mathrm{B}}\right)$ and of prismatic slips (CRSSP) are found to be [27] the following values below.

$$
\begin{aligned}
& \text { CRSS }_{\mathrm{B}} \sim 1.0 \mathrm{MPa} \\
& \text { CRSS }_{\mathrm{P}} \sim 40 \mathrm{MPa}
\end{aligned}
$$

Based on Equation 6 and the CRSS values of the basal and non-basal slip systems reported for the single-crystal Mg alloys [27], the following equation can be written for polycrystalline Mg alloys.

$$
\frac{\tau_{P}}{\tau_{B}}=\frac{40+\Delta \tau}{1+\Delta \tau}
$$

According to this equation, the activity of the prismatic slip would be controlled through the shear stress raised from the hardening effect of the microstructure $(\Delta \tau)$. In our work, the second-phase particles $\left((\mathrm{Mg}, \mathrm{Al})_{2} \mathrm{Ca}\right)$ formed due to the $\mathrm{Ca}$ addition seem to have the effective hardening factor during plastic deformation of this alloy when compared to the AZ31 alloy.

In order to confirm the above-discussed idea, the CRSS values of the various slip systems of the alloys (AZ31 and AZ31-0.5Ca) were calculated by using polycrystalline plasticity simulation based on the viscoplastic self-consistent (VPSC) model [28]. Based on 2000 orientations collected from 
the initial texture of two alloys (Figure 3), the VPSC model was used to simulate the texture until $10 \%$ tensile deformation. The voce hardening law and its parameters were adjusted until the $10 \%$ simulated texture and stress-strain curves matched those experimentally obtained (Figure 9) [29]. The results obtained by the VPSC modeling (Table 4) reveal that the shear stress needed for plastic deformation of the present alloys is greater than that needed for single crystals. This is due to the hardening imposed by the microstructure (grain boundaries effect), which is shown by Equations (6)-(8). More importantly, the CRSS of the basal slip in the AZ31-0.5Ca alloy was higher than that of the AZ31 alloy (49 vs. $57 \mathrm{MPa}$ ). The further hardening recorded for the AZ31-0.5Ca is attributed to the $\mathrm{Ca}$ addition and the formation of the intermetallic compound $\left((\mathrm{Mg}, \mathrm{Al})_{2} \mathrm{Ca}\right)$, which might impede the basal slip. In addition, the relative CRSSs $\left(\tau_{\text {Prismatic }} / \tau_{\text {Basal }}\right)$ of the AZ31-0.5Ca alloy was less than that of the AZ31 (1.5 vs. 2.2). This is consistent with previous works, which reported that the ratios between the effective CRSSs $\left(\tau_{\text {Prismatic }} / \tau_{\text {Basal }}\right.$ ) in Mg alloys get closer to the unity when the hardening induced by the microstructure is high [30]. Such behavior leads to an increase of the activity of the prismatic slip, which can enhance formability. In this case, upon the activation of the prismatic slip, not only is the plasticity enhanced but also the plastic anisotropy is reduced [31]. The alternation of the $\tau_{\text {Prismatic }} / \tau_{\text {Basal }}$ ratio in $\mathrm{Mg}$ alloys by strengthening the basal slip has been reported in several works, which is shown in Figure 10 [32-45]. As compared to the highly formable $\mathrm{Mg}$ alloy containing RE elements [40], the present $\mathrm{Mg}$ alloy (AZ31-0.5Ca) exhibits a reasonable reduced ratio of 1.5 vs. 1.1 in $\mathrm{Mg}-7.6 \%$ Gd-2.4\% Y [45].
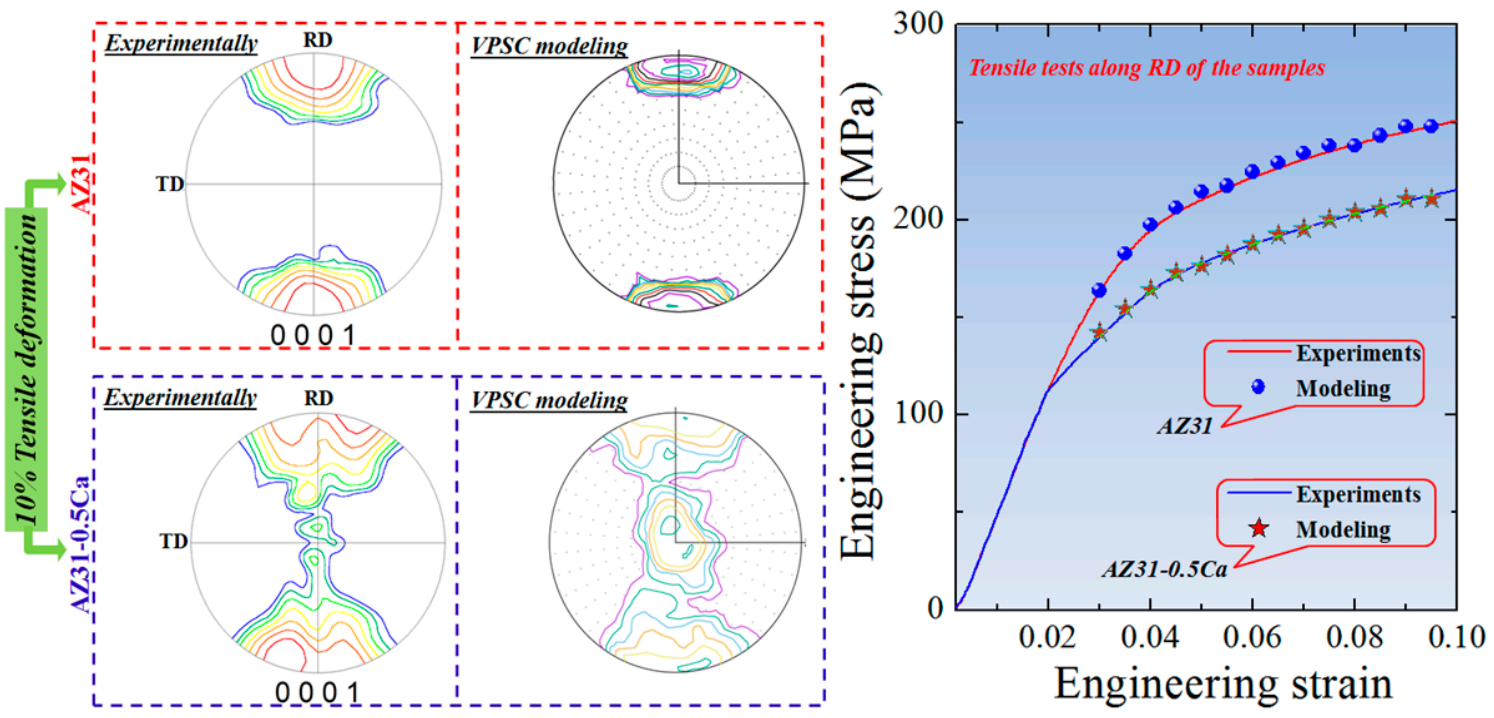

Figure 9. Experimentally observed and VPSC-modeled (0001) pole figures and tensile curves of the 10\%-tensile-deformed AZ31 and AZ31-0.5Ca alloy samples. For tensile curves, the samples of the two alloys were deformed along the RD.

Table 4. CRSS values and hardening parameters of the AZ31 and AZ31-0.5Ca alloys as modeled by the VPSC. All values listed in this table were obtained for tensile tests along the RD of the samples.

\begin{tabular}{cccccc}
\hline Alloy & Deformation Mode & $\boldsymbol{\tau}_{\mathbf{0}}$ & $\boldsymbol{\tau}_{\mathbf{1}}$ & $\boldsymbol{\theta}_{\mathbf{0}}$ & $\boldsymbol{\theta}_{\mathbf{1}}$ \\
\hline \multirow{4}{*}{ AZ31 } & <a > basal slip & 49 & 8 & 122 & 35 \\
& <a > prismatic slip & 108 & 31 & 155 & 11 \\
& <a + c > pyramidal slip & 311 & 76 & 88 & 18 \\
& Tension twin & 6 & 97 & 109 & 25 \\
\hline \multirow{3}{*}{ AZ31-0.5Ca } & <a > basal slip & 57 & 9 & 115 & 62 \\
& <a > prismatic slip & 91 & 37 & 148 & 8 \\
& <a + c pyramidal slip & 305 & 44 & 64 & 22 \\
& Tension twin & 15 & 185 & 110 & 55 \\
\hline
\end{tabular}




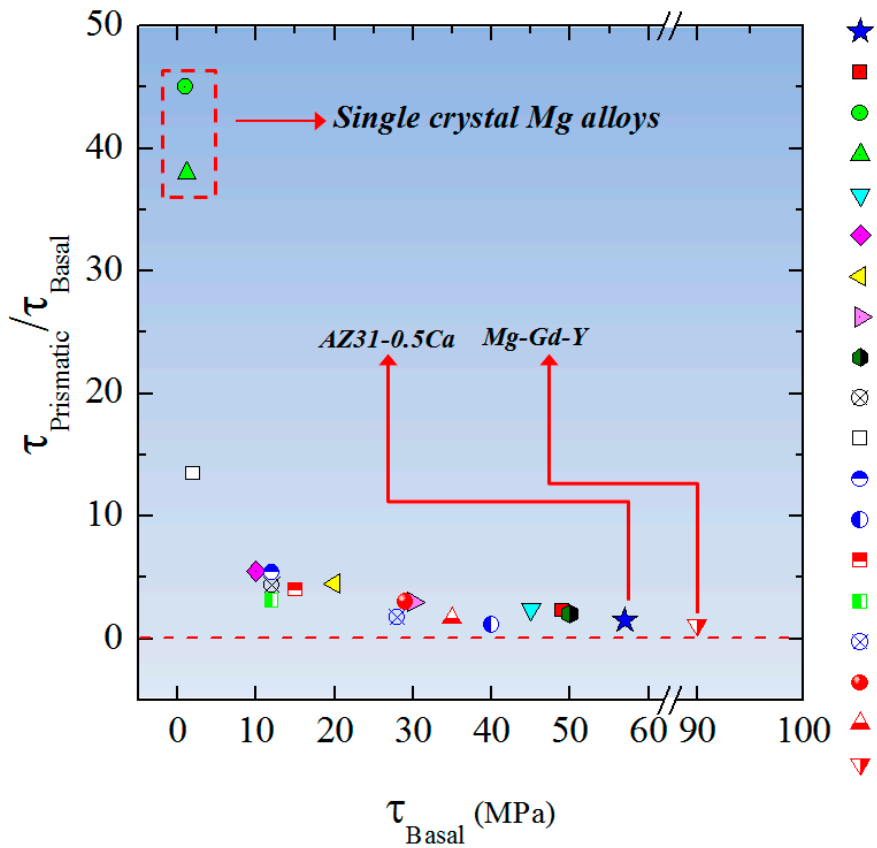

AZ31-0.5Ca (Present work)

AZ31 (Presnet work)

Mg-0.1\% Al single crystal [32]

Mg- $0.25 \% \mathrm{Zn}$ single crystal [33]

AZ31 [34]

AZ31 (Coarse grains $\sim 50 \mu \mathrm{m})$ [35]

AZ31 (Coarse grains $\sim 50 \mu \mathrm{m})$ [36]

AZ31 (Fine grains $\sim 5 \mu \mathrm{m}$ ) [37]

AZ31 (Fine grains $\sim \mu \mathrm{m}$ ) [38]

ZM20 (Fine grains $\sim 17 \mu \mathrm{m}$ ) [39]

ZM30 (Coarse grains $\sim 114 \mu \mathrm{m}$ ) [39]

Mg-1\% Mn- 0.5\% Nd (MN10) [40]

D M-1\% Mn- 1\% Nd (MN11) [40]

AZ31-0.5\% Mn [41]

Mg- $0.3 \%$ Y [42]

ZE10 [43]

ZW41 [44]

Mg-7.6\% Gd-2.4\% Y (Extruded) [45]

Mg-7.6\% Gd-2.4\% Y (Aged) [45]

Figure 10. The ratios between the effective CRSSs $\left(\tau_{\text {Prismatic }} / \tau_{\text {Basal }}\right)$ as a function to the effective CRSS of the basal slip for several $\mathrm{Mg}$ alloys (single-crystal and polycrystalline) [7]. The CRSSs presented in this figure were determined by using various models including the viscoplastic self-consistent (VPSC) model, the elastoplastic self-consistent (EPSC) model, the elastic viscoplastic self-consistent (EVPSC) model, and the Sachs model.

In summary, the present work showed that the modification of the well-known Mg alloy, AZ31, by $0.5 \mathrm{wt}$. \% Ca could lead to a highly formable Mg-based material capable of withstanding a high punch speed at room temperature. This improved formability of the AZ31-0.5Ca alloy was attributed to the role of the $\mathrm{Ca}$ addition in weakening the basal texture during the primary processing. This, in turn, leads to a low plastic anisotropy, which is shown by the three-direction tensile tests. In addition, the IGMA analysis carried out by EBSD on 10\%-tensile-deformed samples revealed the AZ31-0.5Ca alloy, which exhibited a higher activity of the non-basal slip (prismatic slip) during the deformation as compared to the Ca-free alloy (AZ31). The modeling by VPSC confirmed that the high activity of such slip systems in the AZ31-0.5Ca alloy is due to the reduced relative CRSSs ( $\left.\tau_{\text {Prismatic }} / \tau_{\text {Basal }}\right)$. All in all, the formation of $(\mathrm{Mg}, \mathrm{Al})_{2} \mathrm{Ca}$ due to the addition of $0.5 \mathrm{wt}$. \% Ca can weaken the basal texture during the primary processing and increase the activity of the non-basal slips. This leads to low plastic anisotropy, enhanced plasticity, and, as a result, improved formability. Additional experiments are still needed in order to investigate the effect of $(\mathrm{Mg}, \mathrm{Al})_{2} \mathrm{Ca}$ particles on the static and dynamic recrystallization behaviors of the AZ31-0.5Ca alloy.

Author Contributions: K.H. and J.-G.K. designed the experiments and revised the manuscript. U.M.C., T.H.K., S.D.P., and Y.S.K. carried out the experiments. U.M.C. carried out VPSC simulations, analyzed the data, and wrote the manuscript.

Funding: This research was funded by the National Research Foundation (NRF) of South Korea (2017R1C1B5017204).

Acknowledgments: The authors express their gratitude to C. N. Tomé (Material Science and Technology Division, Los Alamos National Laboratory) for providing the VPSC software to conduct the simulations.

Conflicts of Interest: The authors declare no conflicts of interests.

\section{References}

1. Miller, V.M.; Berman, T.D.; Beyerlein, I.J.; Jones, J.W.; Pollock, T.M. Prediction of the plastic anisotropy of Magnesium alloys with synthetic texture and implications for the effect of texture on formability. Mater. Sci. Eng. A 2016, 675, 345-360. [CrossRef] 
2. Hamad, K.; Ko, Y.G. A cross-shear deformation for optimizing the strength and ductility of AZ31 magnesium alloys. Sci. Rep. 2016, 6, 29954. [CrossRef] [PubMed]

3. Zeng, Z.; Nie, J.; Xu, S.; Davies, C.H.J.; Birbilis, N. Super-formable pure magnesium at room temperature. Nat. Commun. 2017, 8, 972. [CrossRef] [PubMed]

4. Al-Samman, T.; Li, X. Sheet texture modification in magnesium-based alloys by selective rare earth alloying. Mater. Sci. Eng. A 2011, 528, 3809-3822. [CrossRef]

5. Levi, G.; Avraham, S.; Zilberov, A.; Bamberger, M. Solidification, solution treatment and age hardening of a Mg-1.6 wt. \% Ca-3.2 wt. \% Zn alloy. Acta Mater. 2006, 54, 523-530. [CrossRef]

6. Agnew, S.R.; Nie, J.F. Preface to the viewpoint set on: The current state of magnesium alloy science and technology. Scr. Mater. 2010, 63, 671-673. [CrossRef]

7. Chaudry, U.M.; Kim, T.H.; Park, S.D.; Kim, Y.S.; Hamad, K.; Kim, J.G. Effects of calcium on the activity of slip systems in AZ31 magnesium alloy. Mater. Sci. Eng. A 2018, 739, 289-294. [CrossRef]

8. Huang, X.; Suzuki, K.; Watazu, A.; Shigematsu, I.; Saito, N. Improvement of formability of Mg-Al-Zn alloy sheet at low temperatures using differential speed rolling. J. Alloys Compd. 2009, 470, 263-268. [CrossRef]

9. Huang, X.; Suzuki, K.; Saito, N. Microstructure and mechanical properties of AZ80 magnesium alloy sheet processed by differential speed rolling. Mater. Sci. Eng. A 2009, 508, 226-233. [CrossRef]

10. Chino, Y.; Ueda, T.; Otomatsu, Y.; Sassa, K.; Huang, X.; Suzuki, K.; Mabuchi, M. Effects of Ca on tensile properties and stretch formability at room temperature in $\mathrm{Mg}-\mathrm{Zn}$ and $\mathrm{Mg}-\mathrm{Al}$ alloys. Metall. Mater. Trans. A 2011, 52, 1477-1482. [CrossRef]

11. Chino, Y.; Huang, X.; Suzuki, K.; Sassa, K.; Mabuchi, M. Influence of Zn concentration on stretch formability at room temperature of Mg-Zn-Ce alloy. Mater. Sci. Eng. A 2010, 528, 566-572. [CrossRef]

12. Gao, L.; Yan, H.; Luo, J.; Luo, A.A.; Chen, R. Microstructure and mechanical properties of a high ductility Mg-Zn-Mn-Ce magnesium alloy. J. Mag. Alloys 2013, 1, 283-291. [CrossRef]

13. Nakata, T.; Xu, C.; Ajima, R.; Shimizu, K.; Kamado, S. Strong and ductile age-hardening Mg-Al-Ca-Mn alloy that can be extruded as fast as aluminum alloys. Acta Mater. 2017, 130, 261-270. [CrossRef]

14. Gröbner, J.; Schmid-Fetzer, R. Key issues in a thermodynamic Mg alloy database. Metall. Mater. Trans. A 2013, 44, 2918-2934. [CrossRef]

15. Yi, S.B.; Park, J.H.; Letzig, D.; Kwon, O.D.; Kainer, K.U.; Kim, J.J. Microstructure and mechanical properties of Ca containing AZX310 alloy sheets produced via twin roll casting technology. Mag. Technol. 2016, 389-393.

16. Rzychon, T.; Chmiela, B. The influence of tin on the microstructure and creep properties of Mg-5Al-3Ca-0.7Sr-0.2Mn magnesium alloy. Solid State Pheom. 2012, 191, 151-158. [CrossRef]

17. Robson, J.; Henry, D.; Davis, B. Particle effects on recrystallization in magnesium-manganese alloys: Particle-stimulated nucleation. Acta Mater. 2009, 57, 2739-2747. [CrossRef]

18. Chun, Y.B.; Battaini, M.; Davies, C.H.J.; Hwang, S.K. Distribution characteristics of in-grain misorientation axes in cold-rolled commercially pure titanium and their correlation with active slip modes. Metall. Mater. Trans. A 2010, 41, 3473-3487. [CrossRef]

19. Davies, C.H.J.; Chun, Y.B. The evolution of In-Grain Misorientation Axes (IGMA) during deformation of wrought magnesium alloy AZ31. Mag. Technol. 2016, 345-349.

20. Hadorn, J.P.; Hantzsche, K.; Yi, S.; Bohlen, J.; Letzig, D.; Wollmershauser, J.A.; Agnew, S.R. Role of solute in texture modification during hot deformation of Mg-rare earth alloys. Metall. Mater. Trans. A 2012, 43, 1347-1362. [CrossRef]

21. Chino, Y.; Kado, M.; Mabuchi, M. Enhancement of tensile ductility and stretch formability of magnesium by addition of 0.2 wt. \%(0.035 at \%) Ce. Mater. Sci. Eng. A 2008, 494, 343-349. [CrossRef]

22. Razavi, S.M.; Foley, D.C.; Karaman, I.; Hartwig, K.T.; Hammond, V.H. Effect of grain size on prismatic slip in Mg-3Al-1Zn alloy. Scr. Mater. 2012, 67, 439-442. [CrossRef]

23. Sandlöbes, S.; Zaefferer, S.; Schestakow, I.; Yi, I.; Gonzalez-Martinez, R. On the role of non basal deformation mechanisms for the ductility of Mg and Mg-Y alloys. Acta Mater. 2011, 59, 429-439. [CrossRef]

24. Yuasa, M.; Miyazawa, N.; Hayashi, M.; Abuchi, M.; Chino, Y. Effect of group II elements on the cold stretch formability of Mg-Zn alloys. Acta Mater. 2015, 83, 294-303. [CrossRef]

25. Lee, J.Y.; Yun, Y.S.; Suh, B.C.; Kim, N.J.; Kim, D.H. Comparison of static recrystallization behavior in hot rolled Mg-3Al-1Zn and Mg-3Zn-0.5Ca sheets. J. Alloys Compd. 2014, 589, 240-246. [CrossRef]

26. Barnett, M.R.; Keshavarz, Z.; Beer, A.G.; Atwell, D. Influence of grain size on the compressive deformation of wrought Mg-3Al-1Zn. Acta Mater. 2004, 54, 4841-4852. [CrossRef] 
27. Hutchinson, W.B.; Barnett, M.R. Effective values of critical resolved shear stress for slip in polycrystalline magnesium and other Hcp metals. Scr. Mater. 2010, 63, 737-740. [CrossRef]

28. Agnew, S.R.; Yoo, M.H.; Tomé, C.N. Application of texture simulation to understanding mechanical behavior of $\mathrm{Mg}$ and solid solution alloys containing Li or Y. Acta Mater. 2001, 49, 4277-4289. [CrossRef]

29. Tang, T.; Shao, Y.; Li, D.; Peng, L.; Wu, P. Polycrystal plasticity simulation of extrusion of magnesium alloy round bar: Effect of strain path non uniformity. J. Alloys Compd. 2018, 730, 161-181. [CrossRef]

30. Sánchez-Martín, R.; Pérez-Prado, M.T.; Segurado, J.; Bohlen, J.; Molina-Aldareguia, J.M. Measuring the critical resolved shear stresses in Mg alloys by instrumented nanoindentation. Acta Mater. 2014, 71, $283-292$. [CrossRef]

31. Hidalgo-Manrique, P.; Yi, S.B.; Bohlen, J.; Letzig, D.; Pérez-Prado, M.T. Effect of Nd additions on extrusion texture development and on slip activity in a Mg-Mn alloy. Metall. Mater. Trans. A 2013, 44, 4819-4829. [CrossRef]

32. Akhtar, A.; Teghtsoonian, E. Solid Solution strengthening of magnesium single crystals-I alloying behavior in basal slip. Acta Metall. 1969, 17, 1339-1349. [CrossRef]

33. Akhtar, A.; Teghtsoonian, E. Substitutional solution hardening of magnesium single crystals. Philos. Mag. 1971, 25, 897-916. [CrossRef]

34. Angnew, S.R. Plastic Anisotropy of magnesium alloy AZ31b sheet. Mag. Technol. 2002, 1, 165-167.

35. Agnew, S.R.; Tomé, C.N.; Brown, D.W.; Holden, T.M.; Vogel, S.C. Study of slip mechanisms in a magnesium alloy by neutron diffraction and modeling. Scr. Mater. 2003, 48, 1003-1008. [CrossRef]

36. Agnew, S.R.; Brown, D.W.; Tomé, C.N. Validating a polycrystal model for the elastoplastic response of magnesium alloy AZ31 using in situ neutron diffraction. Acta Mater. 2006, 54, 4841-4852. [CrossRef]

37. Muránsky, O.; Carr, D.G.; Barnett, M.R.; Oliver, E.C.; Šittner, P. Investigation of deformation mechanisms involved in the plasticity of AZ31 Mg alloy: In situ neutron diffraction and EPSC modelling. Mater. Sci. Eng. A 2008, 496, 14-24. [CrossRef]

38. Barnett, M.R.; Keshavarz, Z.; Ma, X. A semi analytical sachs model for the flow stress of a magnesium alloy. Metall. Mater. Trans. A 2006, 37, 2283-2293. [CrossRef]

39. Muránsky, O.; Barnett, M.R.; Carr, D.G.; Vogel, S.C.; Oliver, E.C. Investigation of deformation twinning in a fine-grained and coarse grained ZM20 Mg alloy: Combined in situ neutron diffraction and acoustic emission. Acta Mater. 2010, 58, 1503-1517. [CrossRef]

40. Herrera-Solaz, V.; Hidalgo-Manrique, P.; Pérez-Prado, M.T.; Letzig, D.; Segurado, J. Effect of rare earth additions on the critical resolved shear stresses of magnesium alloys. Mater. Lett. 2014, 128, 199-203. [CrossRef]

41. Pan, H.; Wang, F.; Feng, M.; Jin, J.; Wu, P. Mechanical behavior and microstructural evolution in rolled Mg-3Al-1Zn-0.5Mn alloy under large strain simple shear. Mat. Sci. Eng. A 2018, 712, 585-591. [CrossRef]

42. Wang, L.; Huang, Z.; Wang, H.; Maldar, A.; Zeng, X. Study of slip activity in Mg-Y alloy by in situ high energy X-ray diffraction microscopy and elastic viscoplastic self-consistent modeling. Acta Mater. 2018, 155, 138-152. [CrossRef]

43. Steglich, D.; Jeong, Y. Texture-based forming limit prediction for Mg sheet alloys ZE10 and AZ31. Int. J. Mech. Sci. 2016, 117, 102-114. [CrossRef]

44. Bohlen, J.; Nurnberg, M.R.; Senn, J.W.; Letzig, D.; Agnew, S.R. The texture and anisotropy of magnesium-zinc-rare earth alloy sheets. Acta Mater. 2007, 55, 2101-2112. [CrossRef]

45. Sun, J.; Jin, L.; Dong, S.; Dong, J.; Zhang, Z.; Wang, F.; Ding, W.; Luo, A.A. A combined electron backscattered diffraction and visco-plastic self consistent analysis on the anisotropic deformation behavior in a Mg-Gd-Y alloy. Mater. Des. 2017, 122, 164-171. [CrossRef]

(C) 2018 by the authors. Licensee MDPI, Basel, Switzerland. This article is an open access article distributed under the terms and conditions of the Creative Commons Attribution (CC BY) license (http:/ / creativecommons.org/licenses/by/4.0/). 